\title{
Sentimentos de mães de recém-nascidos internados em uma unidade de terapia intensiva neonatal
}

\author{
Rosana Alves de Melo ${ }^{1}$; Ana Kariny Costa Araújo ${ }^{2}$; Cristiane Souza Bezerra ${ }^{3}$; Nadja Maria dos Santos ${ }^{4}$; \\ Wanderlúcia Flávia Marques 5; Flávia Emília Cavalcante Valença Fernandes ${ }^{6}$
}

\begin{abstract}
Resumo: O Objetivo foi analisar os sentimentos de mães de recém-nascidos internados na Unidade de Terapia Intensiva Neonatal, sobre as condutas desenvolvidas em seus filhos, pelos profissionais do setor. Método: Pesquisa qualitativa, descritivo-exploratória, com dados coletados por entrevista semiestruturada, com dez mães de recémnascidos internados na UTI Neonatal de um hospital público do interior do Estado de Pernambuco, Brasil, entre novembro e dezembro de 2013. Os dados foram analisados por análise de conteúdo. Resultados: As mães sentemse sensibilizadas com relação a finalidade e importância dos cuidados prestados no setor, para a recuperação adequada de seus filhos, apesar de desconhecerem alguns procedimentos. Conclusão: Ainda há a necessidade de mudança na abordagem do cuidado de enfermagem para que os sentimentos maternos sejam levados em consideração frente as necessidades dos seus filhos e que estas possam participar do cuidado conjuntamente, favorecendo a formação do vínculo afetivo, gerando ambiente mais agradável para a tríade de saúde.
\end{abstract}

Descritores: Recém-nascido; Mães; Unidades de Terapia Intensiva Neonatal; Pessoal de Saúde.

\section{Feelings of mothers of newborns hospitalized in a neonatal intensive care unit}

\begin{abstract}
The objective was to analyze the feelings of mothers of newborns hospitalized in the Neonatal Intensive Care Unit, about the behaviors developed in their children, by the professionals of the sector. Method: Qualitative, descriptive-exploratory study, with data collected by semi-structured interview, with ten mothers of newborns admitted to the neonatal ICU of a public hospital in the interior of the State of Pernambuco, Brazil, between November and December 2013. Data were Analyzed by content analysis. Results: Mothers feel sensitized about the purpose and importance of the care provided in the sector, for the adequate recovery of their children, although they are not aware of some procedures. Conclusion: There is still a need to change the approach to nursing care so that maternal feelings are taken into account in the face of the needs of their children and that these can participate in care together, favoring the formation of the affective bond, generating a more pleasant environment for the health triad.
\end{abstract}

Keywords: Newborn; Mothers; Neonatal Intensive Care Units; Health Personnel.

\footnotetext{
${ }^{1}$ Enfermeira. Docente Assistente. Universidade de Pernambuco. Petrolina, Pernambuco, Brasil. E-mail: rosana.melo@ upe.br.

${ }^{2}$ Enfermeira. Hospital Regional de Juazeiro/BA. Petrolina, Pernambuco, Brasil.

${ }^{3}$ Enfermeira. Empresa Brasileira de Serviços Hospitalares. Salvador, Bahia, Brasil.

${ }^{4}$ Enfermeira. Docente Auxiliar. Universidade de Pernambuco. Petrolina, Pernambuco, Brasil.

${ }^{5}$ Enfermeira. Hospital Dom Malan-IMIP Hospitalar. Petrolina, Pernambuco, Brasil.

${ }^{6}$ Enfermeira. Docente Assistente. Universidade de Pernambuco. Petrolina, Pernambuco, Brasil.

Autor correspondente: Rosana Alves de Melo. Rodovia BR 203, Km 2, s/n - Vila Eduardo, Petrolina/PE, 56328-903. Email: rosana.melo@upe.br. Fone: (87) 3866-6468.
} 
Id on Line Revista Multidisciplinar e de Psicologia

Id on Line Multidisciplinary and Psycology Journal

\section{Introdução}

Diante de muitos nascimentos precoces e da possível necessidade de internamento sob cuidados intensivos, houve nos últimos tempos um aumento no número de leitos de Unidades de Terapia Intensiva Neonatais (UTIN), com a finalidade de sanar as necessidades existentes na prestação de cuidados de alta complexidade, baseado em dinâmica de prestação de serviço de forma organizada e eficiente (ARAÚJO; RODRIGUES, 2010).

A UTIN surgiu como espaço destinado para tratamento de recém-nascidos $(\mathrm{RN})$ prematuros ou não, mas que apresentem algum tipo de problema ao nascer, que possa ser contornado nesse ambiente. Em razão da especificidade da clientela, são dotadas com aparelhos e equipamentos indispensáveis para o cuidado do pequeno paciente (SPIR, ET AL., 2011).

Esse ambiente da UTIN é considerado ambiente hostil e pouco amigável, onde há a necessidade de que os pais acompanhem os filhos no período crucial e significativo. Essa ambiência permeia aparelhos e equipamentos tecnológicos de alta sofisticação, muita luminosidade, barulho de alarmes, além do trânsito constante de pessoas em atribuições profissionais (SCHIMIDT, ET AL., 2012).

No caso de internação numa UTIN, as preocupações e expectativas em relação a criança são muito diferentes, no que diz respeito à mãe e à equipe. Essa equipe se mantém envolvida com a assistência direta e indireta dos $\mathrm{RN}$, na realização de procedimentos técnicos, e também na função de manter comunicação com a mãe e os demais membros da família, tendo sempre a necessidade de expor todos os riscos que o paciente corre (SANTANA; MADEIRA, 2013).

O tempo de internação do RN na unidade neonatal pode se estender por vários meses, e, no cenário dessa hospitalização prolongada, ocorre mudança súbita na vida da família, especialmente da mãe que, num curtíssimo espaço de tempo, torna-se acompanhante do filho, sem que esteja preparada para essa mudança, quase sempre permeada por muito sofrimento (FRELLO; CARRARO, 2012). A equipe tem que estar atenta para favorecer a maior naturalização desse processo, considerando, tanto o tempo prolongado de internação que esses RN demandam, como os efetivos cuidados técnicos e vínculo com as mães que se exige nesses momentos

No cotidiano da UTIN, observa-se a ocorrência de conflitos entre profissionais da assistência e familiares/acompanhantes, manifestados por meio de frieza, indiferença, entre 
Id on Line Revista Multidisciplinar e de Psicologia

Id on Line Multidisciplinary and Psycology Journal

outras atitudes de estranhamento e até de desrespeito mútuo. Ocasionalmente, percebe-se que a presença do acompanhante é vista pela equipe como algo incômodo e cheio de dificuldades de relacionamento dentro da Unidade. Nesse processo conflituoso, verifica-se também certa resistência por parte de familiares no cumprimento de normas e procedimentos recomendados pela equipe de assistência (OLIVEIRA, ET AL., 2013).

Deste modo, a assistência aos pais e o favorecimento de sua participação nos cuidados prestados ao filho, tem sido prioridade das unidades neonatais. Na visita ao filho enfermo em UTIN, é fundamental o acolhimento à mãe, cujos profissionais orientam sobre os cuidados inerentes ao tratamento (PERLIN; OLIVEIRA; GOMES, 2011). Em especial, os profissionais de enfermagem devem adotar a postura de cuidador, priorizando a humanização da assistência à díade mãe-filho (MELO; SOUZA; PAULA, 2013).

Partindo desse pressuposto e do conhecimento de que a relação mãe-equipe favorece o melhor desenvolvimento de condutas desenvolvidas em UTIN, melhorando a qualidade da assistência prestada aos $\mathrm{RN}$, definiu-se a realização desta pesquisa, que teve por objetivo analisar os sentimentos de mães de RN internados na UTIN, sobre as condutas desenvolvidas em seus filhos, pelos profissionais do setor.

\section{Método}

Trata-se de uma pesquisa descritiva, exploratória, de abordagem qualitativa, que se aplica ao estudo das crenças, das opiniões e dos valores dos indivíduos, permitindo o conhecimento do significado das ações e das relações humanas (MINAYO, 2014).

A pesquisa foi realizada na UTIN de um hospital de referência em saúde materno-infantil, localizado no município de Petrolina/PE. A instituição atua nas áreas de assistência médicosocial, pesquisa e extensão, e possui o título de "Hospital Amigo da Criança", cedido pela Organização Mundial de Saúde e Funda das Nações Unidas para a Infância. A UTIN possui seis leitos de neonatologia e conta com a atuação de uma equipe multiprofissional fixa em regime de plantão, composta de enfermeiros, médicos, técnicos de enfermagem e fisioterapeutas, e recebe o suporte de psicólogos, nutricionistas, assistentes sociais, caso seja necessário. 
Id on Line Revista Multidisciplinar e de Psicologia

Id on Line Multidisciplinary and Psycology Journal

A instituição conta com uma residência de apoio dentro do próprio hospital, que garante a permanência da mãe durante toda a internação do filho na UTIN ou em demais setores, caso receba alta da Unidade, sendo-lhes permitido o acesso ao setor de internamento, sempre que desejar, a qualquer hora do dia ou noite, no sentido de favorecer o vínculo mãe-filho e aprimorar o processo de humanização.

Fizeram parte do estudo dez mães de RN internados na UTIN, onde os critérios de inclusão foi que os filhos tivessem um período de internamento no setor de pelo menos quatro dias, tempo mínimo permissível para delinear a experiência existencial dessa mãe com o internamento do filho, e que mantivessem contato com os profissionais do setor; e que, após os esclarecimentos sobre a pesquisa, as mães aceitassem participar, assinando o Termo de Consentimento Livre e Esclarecido. Para definição do quantitativo de participantes, obedecemos o critério de saturação teórica de repetitividade das informações (MINAYO, 2014).

Foram realizadas entrevistas semiestruturadas, sendo registradas por meio de utilização de gravador digital. Da população inicialmente pretendida, foram excluídos os dados de três mães por problemas técnicos no registro/gravação da entrevista e por impossibilidade de agendamento de horários, resultando em um total de dez mães. Os dados referentes à caracterização foram organizados e apresentados ordenadamente, e os que tratam da temática central do estudo foram analisados qualitativamente.

Para tanto, foram submetidos à análise e organizados a partir das questões que nortearam a pesquisa, sendo que as categorias foram alcançadas a partir da leitura exaustiva do material empírico. Foi utilizada a Análise de Conteúdo Temática para análise dos resultados, onde envolveu a leitura compreensiva, exploração do material ou análise e síntese interpretativa, compondo assim as três etapas: pré-análise, exploração do material e tratamento dos resultados com interpretações dos dados (BARDIN, 2010).

De modo a preservar a identidade das participantes, sem perda do enfoque individualizado dos relatos, optou-se por identificar as mães por nomes de flores, que simbolizam, de certa forma, todo o paradoxo da beleza, força e fragilidade da condição/natureza materna retratada neste estudo.

A pesquisa foi aprovado pelo Comitê de Ética em Pesquisa Envolvendo Seres Humanos da Universidade de Pernambuco, conforme Parecer $n^{\circ} 447.599$. Entrevistas ocorreram em 
Id on Line Revista Multidisciplinar e de Psicologia

Id on Line Multidisciplinary and Psycology Journal

consonância com todos os preceitos éticos estabelecidos pela Resolução 466/12 do Conselho Nacional de Saúde/Ministério da Saúde (BRASIL, 2012).

\section{Resultados}

Participaram do estudo 10 mães e suas características podem ser visualizadas no quadro abaixo:

\begin{tabular}{|c|c|c|c|c|c|}
\hline Mães & $\begin{array}{l}\text { Idade } \\
\text { Gestacional }\end{array}$ & $\begin{array}{l}\text { Idade } \\
\text { Anos }\end{array}$ & $\begin{array}{l}\mathbf{N}^{\mathbf{o}} \\
\text { Filhos }\end{array}$ & Escolaridade & Estado civil \\
\hline Acácia & $\begin{array}{l}37 \text { semanas e } 5 \\
\text { dias }\end{array}$ & $10-19$ & 1 & $\begin{array}{l}\text { Fundamental } \\
\text { completo }\end{array}$ & União estável \\
\hline Amarílis & $\begin{array}{l}36 \text { semanas e } 3 \\
\text { dias }\end{array}$ & $20-25$ & 1 & Médio completo & União estável \\
\hline Begônia & $\begin{array}{l}36 \text { semanas e } 18 \\
\text { dias }\end{array}$ & $10-19$ & 1 & $\begin{array}{l}\text { Fundamental } \\
\text { incompleto }\end{array}$ & União estável \\
\hline Carmélia & $\begin{array}{l}35 \text { semanas e } 21 \\
\text { dias }\end{array}$ & $36-45$ & 4 & Médio incompleto & União estável \\
\hline Dália & $\begin{array}{l}36 \text { semanas e } 14 \\
\text { dias }\end{array}$ & $36-45$ & 3 & $\begin{array}{l}\text { Superior } \\
\text { incompleto }\end{array}$ & União estável \\
\hline $\begin{array}{l}\text { Flor do } \\
\text { Campo }\end{array}$ & $\begin{array}{l}34 \text { semanas e } 2 \\
\text { dias }\end{array}$ & $26-35$ & 3 & Médio completo & Casada \\
\hline Gardênia & $\begin{array}{l}37 \text { semanas e } 6 \\
\text { dias }\end{array}$ & $10-19$ & 1 & $\begin{array}{l}\text { Fundamental } \\
\text { completo }\end{array}$ & Solteira \\
\hline Girassol & $\begin{array}{l}34 \text { semanas e } 1 \\
\text { dia }\end{array}$ & $36-45$ & 4 & $\begin{array}{l}\text { Superior } \\
\text { incompleto }\end{array}$ & Casada \\
\hline Hortênsia & $\begin{array}{l}36 \text { semanas e } 10 \\
\text { dias }\end{array}$ & $26-35$ & 2 & $\begin{array}{l}\text { Superior } \\
\text { completo }\end{array}$ & Casada \\
\hline Iris & $\begin{array}{l}36 \text { semanas e } 20 \\
\text { dias }\end{array}$ & $26-35$ & 2 & $\begin{array}{l}\text { Fundamental } \\
\text { completo }\end{array}$ & Solteira \\
\hline
\end{tabular}

Quadro 1 - Caracterização das mães dos recém-nascidos que participaram da pesquisa.

Observa-se que das dez mães entrevistadas, três estavam na faixa etária da adolescência, entre dez a dezenove anos de idade, primíparas e com idade gestacional (IG) entre 37 a 38 semanas, com ensino fundamental incompleto, em média. As demais, estavam na faixa etária entre 20 a 45 anos, multíparas e ensino médio completo. O regime de união estável e casamento formal, sobressaíram nessa pesquisa, no qual se configura uma formação familiar entre os pares, com um período mínimo de convívio de pelo menos um ano. 
Id on Line Revista Multidisciplinar e de Psicologia

Id on Line Multidisciplinary and Psycology Journal

A leitura do conteúdo das entrevistas buscou a temática central do estudo. A análise de conteúdo dos discursos emanados dessa abordagem permitiu construir as categorias que serão trazidas a seguir:

\section{Significado do ambiente Unidade de Terapia Intensiva Neonatal}

Sobre o significado do ambiente Unidade de Terapia Intensiva Neonatal, foi possível analisar nas entrevistas que as mães expressavam medo do ambiente, uma vez que acreditavam que só ficavam internadas as crianças que estavam em estado crítico, sem chance de sobrevida. No entanto, com a estadia do filho, passaram a reconhecer a importância do setor e das condutas desenvolvidas nos seus filhos para favorecer a sobrevida dos mesmos:

É um ambiento que dá medo, mas que sei que vai ser bom para meu filho sobreviver. Se não fosse a UTI e os médicos dela meu filho não teria sobrevivido (Acácia).

Ambiente muito bom, que vai fazer com que meu filho melhore e possa sobreviver. Lugar que antes eu tinha medo, mas agora não tenho mais, por que meu filho está sendo bem cuidado nela, e se não fosse a UTI meu filho tinha morrido (Amarílis).

É a chance de vida para meu filho sobreviver [...]é o que está sustentando ele, ajuda ele a respirar, está mantendo ele vivo para que complete os nove meses. A UTI está sendo minha esperança (Dália).

Houveram mães que referiram não conhecer e não terem ideia do que era um ambiente da UTIN, que não sabiam por que seus filhos precisavam ir para aquele lugar:

Eu não tinha noção de UTI, então está significando muito pra mim, estou aprendendo muito, pois nunca tinha passado por uma situação dessa [...]. Significa uma casa para os pacientes (Girassol).

UTI hoje é o início da vida dos nossos filhos, se não tiver o ambiente Unidade de Terapia Intensiva eles não vão sobreviver [...] é uma importância muito grande esse ambiente (Iris). 
Id on Line Revista Multidisciplinar e de Psicologia

Id on Line Multidisciplinary and Psycology Journal

Observou-se que mesmo não reconhecendo, inicialmente, a finalidade do setor na prestação de cuidados intensivos, as mães tronam-se sensíveis a importância do mesmo ao longo do internamento de seus filhos.

\section{Reconhecimento da importância dos procedimentos realizados na Unidade de Terapia Intensiva Neonatal}

Na abordagem que analisa a percepção das mães sobre o reconhecimento da importância dos procedimentos realizados em seus filhos, observou-se que algumas delas sabem que diversos procedimentos são realizados e que são cruciais, porém não souberam relatar quais eram exatamente:

Não. Mas, não sei por que eu não procuro saber. Eu não gosto (Amarílis).

Sim, aprendi todos. Eles me disseram todos (Hortênsia).

Sei sim. Eles me dizem tudo (Gardênia).

Quanto ao esclarecimento das condutas realizadas por parte dos profissionais, algumas mães tinham, pelo menos, o conhecimento básico sobre esses procedimentos. Porém, em um dos relatos, foi referido que são feitas perguntas sobre os mesmos e a equipe não passa essas informações, quando solicitadas:

São vários [...] fazem aspiração, alimentação, higienização dele. Eles controlam os batimentos do coração, eles falam tudo o que fazem. Uns procedimentos eles pedem pra gente sair para poder evitar o nosso sofrimento em ver nossos filhos chorando (Dália).

Sim. Fazem aspiração, dão banho nele e outros que não sei o nome (Acácia).

Não sei. Vou lá todos os dias e pergunto e eles não dizem nada, dizem apenas que tenho que ir falar com o cirurgião (Begônia). 
Id on Line Revista Multidisciplinar e de Psicologia

Id on Line Multidisciplinary and Psycology Journal

Pelas falas, percebe-se que os RN recebem uma assistência de alta complexidade, mas que em alguns momentos as informações não são repassadas pela equipe, como relatado por algumas mães.

Quanto aos sentimentos das mães sobre a melhoria da qualidade de vida dos filhos, relacionados aos procedimentos realizados, algumas mães são sensíveis ao que é realizado e acrescentam que os profissionais do setor conseguem despertar mais ainda essa percepção quando se mostram dispostos a repassar a informações sobre a importância das condutas realizadas:

É para melhora dele [...] alguns procedimentos eles explicam. Como por exemplo, meu filho estava intubado, e ai eles foram retirar o tubo para que ele possa respirar sem essa ajuda, e ai eles me chamaram para dizer isso, logo depois me chamaram novamente para dizer que meu filho precisa ser intubado de novo (Dália).

Falam tudo que está fazendo, o porquê, a importância de tudo (Gardênia).

Eles passam tudo, e isso é importante por que eles estão sempre descobrindo o que possa vir a acontecer [...] descobrindo diagnósticos (Girassol).

Outras mães mostraram não receber nenhum tipo de esclarecimento por parte dos profissionais, relatando que em alguns momentos até faziam perguntas, no sentido de se sentirem seguras, mas não obtinham respostas, mostrando assim, que ainda há uma comunicação abstrata entre a equipe de saúde e as mães.

Eles não dizem nada, não recebo nenhuma informação deles. Todo dia vou ver meu filho, e perguntei duas vezes e eles não disseram. Não me dizem nem que dia vai ser a outra operação do meu filho (Begônia).

Não sei, é só o que escuto (Amarílis).

Algumas mães, mesmo demonstrando não saber a importância das condutas realizadas em seus filhos durante o internamento, sentiam confiança na equipe de saúde, e por isso não viam necessidade de fazer nenhum questionamento sobre aquilo que elas mesmas não conseguiam compreender: 
Id on Line Revista Multidisciplinar e de Psicologia

Id on Line Multidisciplinary and Psycology Journal

Se eles fazem é por que é importante para ele ficar melhor. Não sei dizer pra que serve cada um, sei que é importante. E confio neles (Acácia).

Eles não passam por que eu ainda não perguntei, eu sei que tenho que me interessar mais. Eu sei que ele está sendo bem tratado (Carmélia).

Não. Eu não procuro saber por que eu sei que o que eles fazem é para o bem do meu filho, para melhorar a sobrevida dele, então eu não procuro saber por que confio neles (Gardênia).

Observa-se que as mães, muitas vezes, mesmo não compreendendo a sistemática de um ambiente de cuidados intensivos, são compreensivas nas condutas realizadas, e confiam na equipe multiprofissional.

\section{Participação das mães na execução dos procedimentos}

Com relação à participação das mães na execução dos procedimentos realizados nos setor, observou-se que a maioria delas preferem não acompanhar os procedimentos realizados em seus filhos, no entanto, algumas questionavam que tinham esse desejo, mas que os profissionais não permitiam:

Não. Por que eu tenho total confiança neles, não preciso acompanhar, mas creio que se a gente quiser eles vão nos permitir (Girassol).

Não sei, não sei se teria coragem de assistir eles fazendo alguma coisa com meu filho (Carmélia).

Todos eu acompanho, só não da aspiração por que eles dizem que é sofrimento, então me dizem para não ir. Mas, se eles me chamarem um dia para ver, eu veria tranquilo (Dália).

Gostaria sim de ver e acompanhar, mas eles não deixam, pede pra sair quando vão fazer algo no meu filho. Mas, eu os entendo (Gardênia). 
Id on Line Revista Multidisciplinar e de Psicologia

Id on Line Multidisciplinary and Psycology Journal

Dessa forma, evidencia-se que algumas mães sentem-se sensibilizadas em participar das atividades desenvolvidas dentro da UTIN, relacionadas aos seus filhos, mas há momentos em que são impedidas por alguns profissionais do setor.

\section{Processo comunicacional entre mãe e equipe multiprofissional}

As informações passadas às mães sobre o quadro clínico dos filhos foi apontado como um fato importante para o enfrentamento da experiência de internalização destes na UTIN. Nesse sentindo, em quase sua totalidade, as mães relataram receber todas as informações da equipe multiprofissional do setor, e sentiram-se sensibilizadas em confiar a eles o cuidados dos filhos:

Todo dia eu pergunto de manhã e de noite e eles me passam como meu filho tá. Mas só a médica que me fala as coisas, se eu perguntar a outra pessoa, eles dizem que tenho que perguntar a médica, que não podem passar nenhuma informação (Carmélia).

Todos passam as informações. Geralmente quem passa é a médica, mas caso ela não esteja os técnicos e enfermeiros me repassam essas informações (Dália).

Equipe toda me passa o que faz com meu filho. Até hoje não tenho do que reclamar da equipe de lá, eles explicam da melhor forma possível. Quando a resposta é dura é por que realmente acontece aquilo com seu filho, às vezes a gente não quer escutar, mas temos que aceitar (Iris).

Observa-se que o processo de comunicação dos profissionais com as mães está presente e favorece a manutenção de uma relação harmoniosa entre eles, bem como a prática da humanização, que ainda é um processo deixa a desejar em diversos cenários assistenciais. 
Id on Line Revista Multidisciplinar e de Psicologia

Id on Line Multidisciplinary and Psycology Journal

\section{Discussão}

As características evidenciadas no perfil das mães pesquisadas nesse estudo, mostraram que pode haver alguma imaturidade materna na vivência das complicações existentes e da internação do filho na UTIN, considerando a idade mais jovem e a menor escolaridade. O fato de vivenciar a experiência precoce do internamento do filho em um ambiente de cuidados intensivos favorece os conflitos emocionais na mãe, e nesse sentido, salienta-se que as mães de primeira viagem precisam de orientações mais precisa e esclarecedoras sobre as possíveis complicações que podem ocorrer durante o parto ou após esse momento, que podem ser decisivos ao internamento do filho em uma UTIN.

A presença de companheiro fixo na vida da mãe é considerado um fator favorável no enfrentamento de situações de estresse, como a internação de um filho em ambiente de cuidados intensivos, até mesmo por se sentir mais segura e por poder compartilhar suas angustias com seu companheiro. A formação familiar com um núcleo estruturado é favorável ao bom desempenho emocional de qualquer indivíduo, até mesmo na capacidade de resiliência em se sobressair de situações estressantes.

Quanto à escolaridade, o fato de todas as mães pesquisadas serem alfabetizadas, tendo em média, pelo menos, dez anos de estudos e nenhuma com escolaridade menor que cinco anos, acredita-se que a maioria consegue compreender melhor o significado do ambiente da UTIN e os procedimentos que são realizados em seus filhos, dentro do setor, e dessa forma, há o favorecimento da relação linear entre elas e a equipe multiprofissional.

O processo de hospitalização acarreta repercussões e impacto variados sobre o paciente e sua família, afetando, especialmente a mãe do RN, no caso da internação neonatal (ANJOS, ET AL., 2012). Isso pode ser atribuído ao fato de haver, teoricamente, a existência de uma unidade inseparável, representada pelo binômio mãe-filho, em que ambos compartilham e são afetados pelas experiências vivenciadas ao longo de todo o processo de gestação, parto e pós-parto.

Resta à mãe, como parte consciente desse binômio, a missão de experimentar todas as angústias que permeiam esse momento, manifestas na forma de sentimentos por vezes antagônicos, como o alívio de receber a alta e poder retornar para junto de sua família, intercalado com a apreensão acerca do futuro de seu filho, que permanece internado. 
Id on Line Revista Multidisciplinar e de Psicologia

Id on Line Multidisciplinary and Psycology Journal

A UTIN expõe o RN a um ambiente sem muita hospitalidade, em que o mesmo convive com ruídos e muita luminosidade, vivenciando a rotina de procedimentos invasivos. $\mathrm{O}$ tratamento especializado, do qual a sobrevivência deste depende, está inteiramente ligado aos desafios encontrados pela família e pelos profissionais (PACHECO, ET AL., 2012). Dessa forma, observou-se que o significado do ambiente de internação desperta sentimentos de medo, angústia e tristeza, presentes nas mães, ao mesmo tempo em que elas reconhecem a importância desse ambiente para o tratamento adequado de seu filho.

Os sentimentos de angústia e incerteza vivenciados pelas mães de RN em UTIN são decorrente do medo da perca de seus filhos, que faz com que estas se deparem com situações de fragilidade que se somam a falta de informação e humanização, levando ao temor mais acentuado do que pode acontecer durante ou após o internamento (SOUZA, ET AL., 2012).

É incontestável que o crescimento tecnológico mudou a sobrevida dos bebês de alto risco. Entretanto, a hostilidade do ambiente hospitalar, o uso de tubos e sondas, o sistema imunológico imaturo e a fragilidade da pele são causas de sofrimento, se comparados ao ambiente acolhedor do ventre materno, em que os mesmos viviam até tão pouco tempo. Esses avanços tecnológicos que vem acontecendo na assistência ao RN podem, algumas vezes, converter o mesmo em objeto de cuidados, enquanto que seus pais ficam apenas como espectadores (VIANA, ET AL., 2012).

Nesse sentido, a incorporação da família no cuidado do filho internado na UTIN, bem como a sua comunicação com a equipe de saúde são estratégias que visam reduzir o impacto negativo da hospitalização, permitindo a continuidade de cuidado por parte da mãe e resultando em um maior vínculo materno, condições indispensáveis para a qualidade de vida e sobrevivência do recém-nascido durante o internamento e após a alta hospitalar.

Corroborando com nossos achados, há pesquisa que aponta falhas na comunicação entre as equipes de saúde da Unidade e as mães, evidenciando o pouco ou o não entendimento do que está sendo realizado com seu filho ou até mesmo o porquê de o mesmo estar internado, assim como o recebimento de informações apenas quando as mães questionam as equipes (PIRES, ET AL., 2013).

A falta de abertura dos profissionais para perceber e esclarecer dúvidas específicas dos casos, e a utilização de linguagem técnica de difícil entendimento para as mães são alguns dos pontos que podem explicar tal deficiência na comunicação entre equipe e familiares e levar 
Id on Line Revista Multidisciplinar e de Psicologia

Id on Line Multidisciplinary and Psycology Journal

essas mães a desenvolverem sentimentos de angústias, como já foi explicitado (ANJOS, et al., 2012). É preciso compreender que muitas mães desconhecem os diversos termos técnicos existentes e quanto menos formal for a transmissão das informações, maior entendimento haverá por parte da família.

A partir disso, percebe-se a importância da ética e do compromisso que os profissionais de saúde ter com os indivíduos assistidos e com seus familiares, frente a assistência prestada, bem como acreditar na possível contribuição que a mãe pode oferecer no desenvolvimento de atividades usuais para com os seu filho, dentro do ambiente de internação, favorecendo assim a melhoria da qualidade da assistência.

É importante enfatizar que essa mãe pode e deve participar de forma parcial, dos cuidados prestados aos seus filhos, como uma forma de compreender o contexto em que está inserida e para familiarizar-se com uma possível necessidade de conviver com um filho que venha a ter sequelas e limitações à longo prazo, após a alta hospitalar (VIANA, et al., 2012).

Autores abordam que a interação entre pais e profissionais é assimétrica, em parte dos casos existentes, pois o profissional, em algumas situações, coloca-se como superior, limitando a comunicação, deixando os pais receosos em manifestarem suas dúvidas (REIS; SANTOS, 2013). E diante desse contexto, é importante saber que o envolvimento da família faz parte da proposta de humanização da assistência hospitalar, que irá contribuir de forma positiva no processo de recuperação do recém-nascido, além de contemplar o direito da mãe em fazer parte deste contexto, de forma mais efetiva.

Com relação a aproximação das mães dos RN internados na UTIN, com os profissionais do setor, há evidência que mostra menores níveis de estresse e angústia de mães em instituição onde há a presença constante de uma equipe multiprofissional integrada e humanizada, e que facilita o processo comunicativo (REIS; SANTOS, 2013). Dessa forma, o cenário em que a atuação da equipe de saúde engloba a troca de informações entre esta e os familiares, contribui de forma significativa na diminuição dos níveis de ansiedade e favorece a contribuição das mães à assistência prestada no ambiente hostil da UTIN.

Entende-se que a conscientização da equipe multiprofissional da UTIN, a importância de sua intervenção, diante dos aspectos emocionais que envolvem as mães no processo de internação do filho, é um processo que sensibiliza positivamente as mães. E diante disso, é essencial que os profissionais valorizem os aspectos psicológicos, reconhecendo situações de 
Id on Line Revista Multidisciplinar e de Psicologia

Id on Line Multidisciplinary and Psycology Journal

vulnerabilidade, bem como se devem resgatar os valores humanísticos no atendimento ao RN, a interação com a família, lhes proporcionado segurança, afetividade e atendimento qualificado (VIANA, et al, 2012).

\section{Considerações Finais}

A internação é sempre um momento difícil em qualquer situação, em que os familiares convivem em instituição com cotidiano que lhes é estranho, que em geral, apresenta situação de dor, sofrimento, angústia e morte. Assim, não cabe apenas a equipe de enfermagem construir comunicação efetiva com os familiares, mas sim a equipe multiprofissional da instituição.

Portanto, as relações estabelecidas entre os familiares e a equipe de assistência tem papel fundamental, sendo viabilizada pelo diálogo, em que as famílias são informadas sobre o quadro de seu filho, e desse modo, passam a sentir-se valorizadas e importantes no processo de recuperação do mesmo.

Nessa perspectiva, os profissionais devem ter abordagem humanizada que respeite as características peculiares desses familiares e situações vivenciadas, reconhecendo a importância das redes de apoio a essa clientela e a relevância na valorização de cada elemento (família e equipe) para o sucesso e a otimização do enfrentamento familiar.

Espera-se que esse estudo traga reflexões aos profissionais atuantes nesses setores, conduzindo reflexão centrada nas fragilidades e potencialidades específicas de cada familiar, e que dessa forma traga para esses sujeitos, habilidades individuais que os ajudem a superar as dificuldades. Dessa forma, entendemos que a chave para uma boa relação família/mãe e equipe, é o diálogo e a humanização da equipe.

\section{Referências}

ARAÚJO, B.B.M.; RODRIGUES, B.M.R.D. Vivências e perspectivas maternas na internação do filho prematuro em Unidade de Tratamento Intensivo Neonatal. Rev Esc Enferm USP 2010; 44(4):865-72 
Id on Line Revista Multidisciplinar e de Psicologia

Id on Line Multidisciplinary and Psycology Journal

ANJOS, L.S. ET AL. Percepções maternas sobre o nascimento de um filho prematuro e cuidados após a alta. Rev. Bras. Enferm. 2012; 65(4):571-7.

BARDIN, L. Análise de conteúdo. Edição revisada e ampliada. São Paulo: Ed. 70; 2010.

BRASIL. Ministério da Saúde. Conselho Nacional de Saúde, Comissão Nacional de Ética em Pesquisa. Resolução $N^{\circ} 466$ de 12 de dezembro de 2012: aprova as diretrizes e normas regulamentadoras de pesquisa envolvendo seres humanos. Brasília: Ministério da Saúde; 2012.

FRELLO, A.T.; CARRARO, T.E. Enfermagem e a relação com as mães de neonatos em Unidade de Terapia Intensiva Neonatal. Rev. Bras. Enferm. 2012; 65(3):514-21.

MELO, R.C.J.; SOUZA, I.O.S; PAULA, C.C. Enfermagem neonatal: o sentido existencial do cuidado na Unidade de Terapia Intensiva. Rev. Bras. Enferm. 2013; 66(5):656-62.

MINAYO, M.C.S. O desafio do conhecimento: pesquisa qualitativa em saúde. 14 ed. São Paulo: Hucitec; 2014.

OLIVEIRA, K. ET AL. Vivências de familiares no proceso de nascimento e internação de seus filhos em UTI Neonatal. Rev. Esc. Anna Nery (impr.) 2013 jan -mar; 17 (1):46-53.

PACHECO, S.T.A. ET AL. Uso do copinho em Unidade de Terapia Intensiva Neonatal: dificuldades e facilidades maternas. Rev. Pesq. Cuid. Fundam. (online) 2012. jul./set. 4(3):2554-60

PERLIN, D.A.; OLIVEIRA, S.M.; GOMES, G.C. A criança na Unidade de Terapia Intensiva Neonatal: imacto da primeira visita da mãe. Rev. Gaúcha Enferm. Porto Alegre (RS). 2011 set32(3):458-64.

PIRES, L.P. ET AL. Estudo exploratório das informações recebidas pelas mães de recémnascidos egressos de unidades de terapia intensiva neonatal de juiz de fora. Rev. APS. 2013; $16(1): 10-9$.

REIS, A.T.; SANTOS, R.S. Maternagem ao recém-nascido cirúrgico: bases para a assistência de enfermagem. Rev. Bras. Enferm. 2013; 66(1):110-5.

SPIR, E.G. ET AL. The perception of the companion on the humanization of care in a neonatal unit. Rev. Esc. Enferm. USP. 2011; 45(5):1048-54.

SCHIMIDT, K.T. ET AL. A primeira visita ao filho internado na Unidade de Terapia Intensiva Neonatal: percepção dos pais. Rev. Esc. Anna Nery. 2012 jan-mar; 16 (1):73-81.

SANTANA, E.F.M, MADEIRA, L.M. A mãe acompanhante na unidade de terapia intensiva neonatal: desafios para a equipe assistencial. Rev. Enferm. Cent. Min. 2013; 3(1):475-87.

SOUSA, A.M. ET AL. Sentimentos expressos por mães de neonatos prematuros internados na UTI neonatal. Rev. Pesqu. Cuid. Fundam. (online) 2012. 3(5): 100-110. 
Id on Line Revista Multidisciplinar e de Psicologia

Id on Line Multidisciplinary and Psycology Journal

VIANA, M.C.A. ET AL. Comunicação entre profissionais e mães em Unidade de Terapia Intensiva Neonatal: uma tecnologia leve de enfermagem. Rev. Nursing (São Paulo). Ago 2012. 15(171): 422-426.

\section{Como citar este artigo (Formato ABNT):}

MELO, S.A.; ARAÚJO, A.K.C.; BEZERRA, C.S.; SANTOS, N.M.; MARQUES, W.F.; FERNANDES, F.E.C.V. Sentimentos de mães de recém-nascidos internados em uma unidade de terapia intensiva neonatal. Id on Line Revista Multidisciplinar e de Psicologia, Nov-Dez. de 2016, vol.10, n.32, p. 88-103. ISSN: 1981-1179.

Recebido: $14 / 11 / 2016$

Aceito: $17 / 11 / 2016$ 